\section{KEBIJAKAN POLITIK MUAWIYAH}

\section{Khairuddin}

Program Pascasarjana UIN Suska Riau

Email: kh4iruddin@yahoo.co.id

\section{Abstract}

Muawiyah Policy: Medina states period ended with the death of Caliph Ali ibn Abi Talib. Figure that rises to politics and governance is Muawiyah ibn Abu Sufyan, the governor of the territory since ancient caliphate of Sham Umar bin Khattab. He is the founder and also the first Caliph of Umayyad dynasty. Among the policy of Muawiyah is a secular position and serves as the executive head of government. Muawiyah is more direct policies on the expansion of political power or territorial expansion of state territorial. More priority to those bloody Arabs sit in government, non-Arab people do not have the same opportunity with the extent of Arab people. Qadi (judge) has the freedom to decide the case. In addition, it does not leave the element of religion in government. Religious formalities are still adhered and sometimes still display the image of himself as a warrior of Islam. The power of the caliph is absolute. So, the appearance of the Umayyad dynasty rule which takes the form of monarchy, is the second half of the practice of government in the history of the Islamic followers.

Keywords: Siyasah, Syar'iyah, Political.

\section{Pendahuluan}

Syari'at tidak dapat tegak tanpa dukungan politik dan pemerintah. Ini dapat disimpulkan dari argumentasi Ibn Taimiyah tentang pentingnya kepemimpinan umat. Ia membangun logika berpikirnya dengan menjelaskan bahwa Allah mewajibkan amar ma'ruf dan nabi munkar, tetapi itu tidak akan dapat wujud tanpa (atau paling tidak, tidak akan sempurna) kalau tidak ditopang dengan kekuatan politik dan pemerintahan. Demikian juga seluruh kewajiban yang disyari’atkan Allah SWT kepada hamba-Nya. ${ }^{1}$ Hal ini dapat dibuktikan dengan pendekatan analisis historis.

Dalam sejarah perkembangan pemikiran hukum Islam, terdapat beberapa pemikir hukum Islam (mujtahid). Dari beberapa pemikir tersebut hanya melembaga dalam empat aliran pemikiran (mazhab) dan terakhir menjadi enam mazhab ditambah dengan mazhab Ja'fari dan mazhab Zhahiriy. ${ }^{2}$ Pelembagaan pemikiran mujtahid tersebut, selain upaya murid-murid yang mengembangkan pemikiran guru mereka, juga tidak terlepas dari kebijakan politik. Pemikiran Abu Hanifah baru membumi ketika Abu Yusuf diangkat menjadi Qadhi alQudhat, sehingga pemikiran-pemikiran Abu Hanifah dapat dijadikan sebagai materi hukum di pengadilan. ${ }^{3}$ Dalam bukunya Al-Kharaj yang dipersembahkan kepada Khalifah Harun al-Rasyid, Abu Yusuf memberi pesan dalam kata pengantarnya : "Tegakkanlah kebenaran, jauhkan diri anda dari memutuskan segala bentuk perkara dengan hawa nafsu dan kemarahan. Pandanglah setiap manusia itu sama, yang dekat ataupun yang jauh. Saya menasihati anda ya Amiril Mukminin agar menjaga apa yang diperintahkan Allah SWT dan memelihara amanah-Nya".

${ }^{1}$ Lihat Syeikh al-Islam Taqiy al-Din Ahmad ibn Taimiyah, Al-Siyasah alSyar'iyyah fi Ishlah al-Ra'iy wa al-Ra'izah, (Beirut: Daar al-Kutub al-Ilmiyah, 2000), hlm. 138

2 Ini dapat dilihat dengan munculnya karya Muhammad Jawad Mughniyah, Figh Lima Mazhab. Penulis memasukkan mazhab Ja'fariy sebagai mazhab kelima. Dalam kajian ushulnya Abu Zahrah menulis buku Ushul al-Figh al-Ja'fariy. Mazhab Zhahiriy sebenarnya telah disusun dasar-dasar berpikir serta aplikasinya dalam fiqh oleh Ibn Hazm dengan karyanya dalam kajian Ushul, Al-Ibkam Fi Ushul al-Abkam dan dalam kajian fiqh, Al-Muballa bi al-Atsar. Akhir-akhir ini mazhab Zhahiriy menjadi lebih dikenal setelah adanya tesis Muhammad Muhammad Abid al-Jabiri yang memberikan kesimpulan bahwa Ibn Hazm adalah peletak dasar-dasar berpikir burbani dalam tradisi keilmuan Arab (Islam) dengan karyanya Takwin al-'Aql al'Arab dan telah diterjemahkan dalam bahasa Indonesia, Formasi Nalar Arab.

${ }^{3}$ Lihat al-Syeikh Muhammad al-Khudlariy Bek, Tarikh al-Tasyri' al-Islamiy, (Jakarta: Daar al-Kutub al-Islamiyah, 2008), hlm. 147 Lihat juga Mun'im A. Sirry, Sejarah Fiqih Islam : Sebuah Pengantar, (Surabaya: Risalah Gusti, 1996), hlm. 61-62 162 
Di sisi lain, mazhab Auza'iy, umpamanya, yang masih se zaman dengan Abu Hanifah, menjadi lenyap. Pendapatnya hanya dapat ditemukan dalam kitab-kitab fiqh perbandingan tetapi tidak eksis sebagai mazhab resmi karena tidak didukung oleh politik. Sebenarnya mazhab Auza'iy ini pernah menjadi mazhab resmi di Syiria hingga abad ke sepuluh. Tetapi ketika Abu Zar'ah Muhammad bin Usman dari mazhab Syafii diangkat sebagai hakim di Damaskus. Abu Zar'ah senantiasa memberikan hadiah uang tunai sebesar seratus dinar bagi siapapun yang sanggup menghapal buku Mukhtashar al-Muzanni (termasuk buku pokok dalam mazhab Syafii). Secara alamiah mazhab Syafii menjadi lebih dikenal karena dukungan politik dan mazhab Auza'iy perlahan ditinggalkan. ${ }^{4}$ Ini adalah dua dari banyak kasus tentang wujud atau tidaknya hukum syar'i ketika didukung atau tidak didukung oleh politik.

\section{Pengertian Siyasah Syar'iyyah}

Siyasah Syar'iyyah terdiri dari dua kata, siyasah dan syar'iyah. Kata siyasah merupakan bentukan dari ساس - سوس - سياسة yang berarti mensiasati. Ibn Manzhur juga menyebutkan makna القيام على الشيء بما يصلحه , berupaya menegakkan sesuatu yang diyakini memiliki kemaslahatan. ${ }^{5}$ Adapun kata syar'iyyah merupakan bentukan dari kata - شع -شرع - شرعة شريعة yang diberi tambahan ya nisbah, mempunyai arti datang, segera dan juga diartikan sebagai sumber air. Ibn Manzhur juga menyebutkan

${ }^{4}$ Lihat Abu Ameenah Bilal Philips alih bahasa oleh M. Fauzi Arifin, Asal Usul dan Perkembangan Fiqh : Analisis Historis atas Marhab, Doktrin dan Kontribusi, (Bandung: Nusamedia, 2005), hlm. 93-94 108

${ }^{5}$ Lihat Ibn Manzur, Lisan al-Arab, (Beirut: Daar al-Shadir, 1990), jilid 6, hlm. makna ما سن الله من الدين و أمر به atau ما شرع الله للعباد, segala sesuatu yang disyari'atkan Allah kepada hambanya berupa perintah agama. ${ }^{6}$ Berdasarkan pengertian secara bahasa ini dapat dipahami bahwa siyasah syar'iyyah adalah upaya menegakkan syar'i yang diyakini penguasa memiliki kemaslahatan.

Abdul Wahab Khalaf mengemukakan sebagaimana dikutip oleh Prof. Dr. H. A. Djazuli, siyasah syar'iyah adalah pengurusan hal-hal yang bersifat umum bagi negara Islam dengan cara menjamin perwujudan kemaslahatan dan terhindar dari segala kemudharatan, selama dalam batas-batas yang ditentukan syarak dan kaidah-kaidah umum yang berlaku, sekalipun upaya ini tidak sejalan dengan ijtihad ulama. ${ }^{7}$ Ibn alQayyim al-Jauziyah mengutip pendapat Imam Syafii dan Ibn 'Aqil. Syafii menyebutkan:

$$
\text { لاسياسة إلا ما وافق الشرع }
$$

"siyasah diperbolehkan hanya dalam persoalan yang sesuai dengan syarak". Sedangkan Ibn 'Aqil menyebutkan:

$$
\text { صلى الله عليه وسلم ولا نزل به وحي. السياسة ما كان فعلا بكون معه الناس أقرب إلى الصلاح وأبعد عن الفساد وإن لم بضعه الرسول }
$$

"Siyasah adalah upaya yang dapat dilakukan dalam rangka mendekatkan manusia kepada kebaikan dan menjauhkannya dari kebinasaan, meskipun tidak ada wahyu dan hadis yang mengaturnya". Ketika menjelaskan pengertian siyasah syar'iyah, Ibn al-Qayyim memilih

${ }^{6}$ Ibn Manzhur, Lisan al-Arab, jilid 8, hlm. 175 - 176

${ }^{7}$ Lihat A. Djazuli, Fiqh Siyasah : Implementasi Kemaslahatan Umat dalam Ramburambu Syari'ah, (Jakarta: Kencana, 2007), hlm. 28

8 Lihat Muhammad bin Abu Bakar bin Qayyim al-Jauziyah (selanjutnya ditulis Ibn Qayyim) ditahqiq oleh Muhammad Jamil Ghazi, Al-Thuruq alHukumiyyah fi al-Siyasah al-Syar'iyyah, (Kairo: Mathba'ah al-Madaniy, t.th.), hlm. 16 164 
pendapat Ibn 'Aqil ini dengan menambahkan komentar "asalkan tidak bertentangan dengan prinsip umum syari'at Islam". "Apabila pengertian siyasah syar'yyah tersebut dipahami lebih lanjut, maka dapat dikatakan bahwa siyasah syar'iyyah mengandung beberapa unsur; [1] ada kebijakan, hukum atau aturan; [2] dilakukan oleh penguasa; [3] dimaksudkan untuk kemaslahatan rakyat; dan [4] tidak bertentangan dengan prinsip umum syari'at Islam.

Terdapat beberapa tawaran tentang pembidangan dalam kajian tentang siyasah syar'iyyah. Hasbi Ash Shiddieqy menawarkan delapan pembidangan yang meliputi: [1] Siyasah Dusturiyah Syariyah; [2] Siyasah Tasyri'iyyah Syar'iyyah; [3] Siyasah Qadhaiyah Syar'iyab; [4] Siyasab Maliyah Syariyah; [5] Siyasah Idariyah Syariyab; [6] Siyasah Kharijiyah Syariyyah / Siyasah Dauliyah; [7] Siyasah Tanfiziyah Syar'iyah; dan [8] Siyasah Harbiyyah Syar'iyyah. Tawaran lain adalah terdapat empat pembidangan yang meliputi: [1] Siyasah Dusturiyah; [2] Siyasah Maliyah; [3] Siyasah Dauliyab; dan [4] Siyasah Harbiyah.

Dalam tulisan ini penulis melakukan pembidangan Siyasah Syar'iyah yang meliputi tiga aspek penting : [1] Siyasah Dusturiyah (tata negara), yang meliputi aturan pemerintahan, prinsip dasar yang berkaitan dengan pendirian suatu pemerintahan serta aturan yang berkaitan dengan hak-hak pribadi, masyarakat dan negara; [2] Siyasab Kharijiyah (luar negeri), meliputi hubungan negara dengan negara lainnya, kaidah yang melandasi hubungan tersebut dan tata aturan tentang keadaan perang dan damai; dan [3] Siyasab Maliyah (harta), meliputi sumber-sumber keuangan dan belanja negara.

\section{Sekilas Tentang Dinasti Umayyah}

Periode negara Madinah berakhir dengan wafatnya Khalifah Ali bin Abi Thalib. Tokoh yang naik ke panggung politik dan pemerintahan adalah Muawiyah bin Abu Sufyan, Gubernur wilayah

${ }^{9}$ Ibid.
Syam sejak zaman Khalifah Umar bin Khattab. Ia adalah pendiri dan Khalifah pertama Dinasti ini. Muawiyah dilahirkan kira-kira 15 tahun sebelum Hijrah. Ia masuk Islam pada hari penaklukan kota Mekah bersama penduduk kota Mekah lainnya. Waktu itu ia berusia 23 tahun. Rasulullah SAW ingin sekali mendekatkan orang-orang yang baru masuk Islam diantara pemimpin-pemimpin keluarga ternama kepadanya, agar perhatian mereka kepada Islam itu dapat terjamin dan agar ajaran-ajaran Islam itu benar-benar tertanam dalam hati mereka. Sebab itu Rasulullah SAW berusaha supaya Muawiyah menjadi lebih akrab kepada beliau. Muawiyah bin Abu Sofyan diangkat menjadi anggota dari sidang penulis wahyu. ${ }^{10}$ Muawiyah banyak meriwayatkan hadis, baik yang langsung dari Rasulullah SAW ataupun dari sahabatsahabat terkemuka, termasuk dari saudara perempuannya, Habibah binti Abu Sofyan, istri Rasulullah SAW dan dari Abdullah bin Abbas, Sa'id bin Musayyab serta sahabat lainnya. ${ }^{11}$

Terbentuknya Dinasti ini dan Muawiyah memangku jabatan Khalifah secara resmi, menurut ahli sejarah, terjadi pada tahun $661 \mathrm{M}$ / $41 \mathrm{H}$. bukan pada pertengahan tahun $660 \mathrm{M}$ / $40 \mathrm{H}$ pada saat Umayyah memproklamerkan diri menjadi Khalifah di Iliya (Palestina), setelah pihaknya dinyatakan oleh majelis tahkim sebagai pemenang. ${ }^{12}$ Peristiwa itu terjadi setelah Hasan bin Ali yang dibaiat oleh pengikut setia Ali menjadi Khalifah, sebagai pengganti Ali bin Abi Thalib, mengundurkan diri dari gelanggang politik. Sebab ia tidak ingin lagi terjadi pertumpahan darah yang lebih besar, dan menyerahkan kekuasaan sepenuhnya kepada Muawiyah. Langkah penting Hasan bin Ali ini dapat dikatakan sebagai upaya rekonsiliasi umat Islam yang

${ }^{10}$ Lihat al-Hafizh Jalal al-Din Abd al-Rahman al-Suyuthi (selanjutnya ditulis Suyuti), Tarikh al-Khulafa, (t.tp: Daar al-Kutub al-Islamiyah, t.th.), hlm. 181

${ }^{11}$ Suyuti menjelaskan bahwa hadis yang diriwayatkan Muawiyah bin Abi Sofyan dari Rasulullah SAW jumlahnya mencapai 163 hadis. Lihat Suyuti, Ibid.

${ }^{12}$ Lihat al-Imam al-'Allamah 'Umdat al-Muarrikhin Abu Hasan Ali bin Abu al-Karam Muhammad bin Muhammad bin Abd al-Karim bin Abd al-Wahid alSyaibaniy, lebih dikenal dengan Ibn Atsir (selanjutnya ditulis Ibn Atsir), Al-Kamil fi al-Tarikh, (Beirut: Daar al-Kutub al-Ilmiah, 1998), jilid 3, hlm. 272 
terpecah belah. Karenanya peristiwa itu dalam sejarah Islam dikenal dengan tahun persatuan ('amm al-jama'ah). ${ }^{13}$ Yaitu episode sejarah yang mempersatukan umat kembali berada di bawah kekuasaan seorang Khalifah. Rujuk dan perdamaian antara Hasan dan Muawiyah setelah Muawiyah bersedia memenuhi persyaratan yang diajukan oleh Hasan, yaitu Muawiyah harus menjamin keamanan dan keselamatan jiwa dan harta keturunan Ali bin dan pendukungnya. Pernyataan ini diterima Muawiyah dan dibuat secara tertulis. Persetujuan Muawiyah ini diimbangi oleh Hasan bin Ali dengan membaiatnya. Rakyat juga menunjukkan ketaatan dengan membaiatnya.

Muawiyah dikenal sebagai seorang politikus dan administrator yang pandai. Umar bin Khattab sendiri pernah menilainya sebagai seorang yang cakap dalam urusan politik dan pemerintahan, cerdas dan jujur. Ia juga dikenal sebagai seorang negarawan yang ahli bersiasat, piawai dalam merancang taktik dan strategi, disamping kegigihan dan keuletan serta kesediaannya menempuh segala cara dalam berjuang, untuk mencapai cita-citanya karena pertimbangan politik dan tuntutan situasi. Dengan kemampuan tersebut dan bakat yang dimilikinya, Muawiyah dinilai berhasil merekrut para pemuka masyarakat, politikus dan administrator bergabung ke dalam sistem yang ia bangun untuk memperkuat posisi kepemimpinannya. Muawiyah juga dikenal berwatak tegas dan keras, tetapi juga bersifat toleran dan lapang dada. Hal ini dapat dilihat dalam ucapannya yang terkenal sebagai prinsip yang ia terapkan dalam memimpin seperti yang dijelaskan oleh Said ibn al-'Ash:

${ }^{13}$ Lihat Abu al-Fida' al-Hafizh ibn Katsir al-Dimasyqiy (selanjutnya ditulis Ibn Katsir), Al-Bidayah wa al-Nihayah, (Beirut: Daar al-Kutub al-Ilmiah, 2001), jilid 8, hlm. 17

$$
\begin{aligned}
& \text { سمعت معاوية يوما يقول : لا أضع سيفي حيث يكيني سوطي، ولا أضع سوطي حيث كکنين } \\
& \text { لساني، ولو أن بيني وبين الناس شعرة مااقطت. قيل وكيف إ أمير المؤمنبن ؟ قال : كانوا إذا مدوها خليتها } \\
& \text { وإذا خلوها مددنها ." }
\end{aligned}
$$

"Aku tidak mempergunakan pedangku kalau cambuk saja sudah cukup, dan tidak pula kupergunakan cambukku kalau perkataan saja sudah memadai, andaikata aku dengan orang lain memperebutkan sehelai rambut, rambut itu tidak akan putus. Dikatakan, apa maksudnya ya Amir al-Mukminin ? Ia menjawab: Apabila mereka mengencangkannya aku kendorkan dan bila mereka mengendorkannya akan kukencangkan".

Dinasti Umayyah di Syam berkuasa selama 91 tahun dan dipimpin oleh 14 orang Khalifah yang diwariskan secara turun temurun dalam lingkup keluarga Umaiyah. Untuk lebih jelasnya dapan dilihat pada bagan berikut:
${ }^{14}$ Lihat Ahmad bin Ishak bin Ja'far bin Wahab bin Wadhih al-Ya'kubiy alBagdadiy, Tarikh al-Ya'qubiy, (Beirut: Daar al-Kutub al-Ilmiah, 1999), Juz 2, hlm. 166 
Dalam bidang Siyasab Dusturiyah, telah terdapat beberapa perbedaan dibandingkan dengan pada masa nabi dan Khulafa alRasyidin. Perbedaan tersebut dapat dilihat dalam kebijakan politik penguasa Dinasti ini seperti:

Pertama, pemindahan pusat pemerintahan dari Madinah ke Dahaskus. I Pemindahan pusat pemerintahan ini dilakukan oleh Khalifah Dinasti Umayyah pertama, Muawiyah bin Abi Sufyan.

I Madinah sebagai pusat pemerintahan bagi banyak katangan dianggap sebagai sunnah nabi Muhammad SAW yang harus dipertahankan. Karena perbuatan/kebijakan nabi menjadikan Madinah sebag harus diikuti. ${ }^{15}$ Karena itu pula Khalifah sebelumnya (Khulafa alRasyidin) tidak satu pun di antara mereka yang memindahkan pusat pemerintahan tersebut. Keputusan Muawiyah bin Abi Sufyan ini merupakan Siyasah Syar'iyah. Barangkali keputusan tersebut didasari oleh berbagai pertimbangan : [1] Berdasarkan pertimbangan idiologi keagamaan tidak ada sebuah nash sharih yang dapat dipertanggung jawabkan secara syar'iy mewajibkan Madinah sebagai pusat pemerintahan, sebaliknya juga tidak ada larangan syar'iy yang melarang pemindahan pusat pemerintahan tersebut. Dengan demikian dapat dikembalikan kepada kaedah dasar al-ashl fi al-asya' al-ibahab; [2] Pertimbangan politis dan keamanan dalam rangka mewujudkan kemaslahatan bagi masyarakat pada waktu itu. Damaskus jauh dari Kufah, pusat kaum Syi'ah yang mendukung Ali bin Abi Thalib dan jauh dari Hijaz, tempat tinggal mayoritas Bani Hasyim dan Bani Umayyah, sehingga bisa terhindar dari konflik yang lebih tajam antara dua Bani tersebut dalam memperebutkan kekuasaan; [3] Pertimbangan strategi pemerintahan. Damaskus yang terletak di wilayah Syam (Suria) secara turun temurun dalam satu keluarga besar Bani Umayyah. Secara individual perlu diakui adanya Khalifah-khalifah yang bijaksana, arif, adil, jujur dan memiliki kepedulian yang tinggi dalam mensejahterakan rakyatnya seperti yang dilakukan oleh Umar bin Abdul Aziz.

${ }^{15}$ Ini akan jelas ketika dikutip penjelasan sunnah dalam perspektif ahli hadis yang cenderung mendefenisikan sunnah ebagai "segala sesuatu yang berasal dari nabi Muhammad SAW berupa perkataan, perbuatan, ketetapan dan bahkan sifat, baik sebelum diangkat menjadi rasul maupun setelah diangkat menjadi rasul”. 
adalah daerah yang berada di bawah genggaman pengaruh Muawiyah bin Abu Sufyan selama 20 tahun sejak ia diangkat menjadi Gubernur di distrik itu pada zaman Khalifah Umar bin Khattab. Sehingga ini sebagai strategi bagi Muawiyah untuk membangun kekuatan politik dalam rangka mewujudkan cita-citanya. Hal ini dapat dipahami karena secara psikologis masyarakat Damaskus telah mengenal dengan baik kebijakan politik Muawiyah bin Abi Sufyan yang telah memimpin mereka selama 20 tahun.

Kedua, kebijakan dan keputusan politik penting yang dibuat Khalifah Muawiyah bin Abi Sufyan adalah mengubah sistem pemerintahan yang berbentuk khilafah dan bercorak syura atau demokratis menjadi sistem monarki (kerajaan) dengan mengangkat putranya, Yazid bin Muawiyah menjadi putra mahkota untuk menggantikannya sebagai Khalifah. ${ }^{16}$

Hal ini berarti suksesi kepemimpinan berlangsung secara turun temurun yang diikuti oleh Khalifah-khalifah pengganti Muawiyah bin Abi Sufyan. Dengan demikian Muawiyah dituding yang mempelopori meninggalkan tradisi di zaman Khulafa al-Rasyidin di mana Khalifah ditetapkan melalui pemilihan oleh umat. Lebih dari itu, Muawiyah telah dianggap melanggar asas musyawarah yang diperintahkan alQur'an agar segala urusan diputuskan berdasarkan musyawarah. Karena itu, keputusan politik Muawiyah itu mendapat protes dari umat Islam golongan Syi'ah, pendukung Ali bin Abi Thalib, Abd alRahman bin Abu bakar, Husein bin Ali dan Abdullah bin Zubeir. Bahkan tokoh kalangan masyarakat Madinah mengadakan dialog dengan Muawiyah. Mereka menyarankan agar ia mengikuti jejak Rasulullah SAW atau Abu Bakar al-Shiddiq atau Umar bin Khattab dalam urusan Khalifah tidak mendahulukan qabilab dari umat. Muawiyah tidak menggubris saran ini. Alasan yang dikemukakan karena ia khawatir akan timbul kekacauan dan akan mengancam stabilitas keamanan kalau ia tidak mengangkat putra mahkota sebagai

\footnotetext{
${ }^{16}$ Ibn Atsir, Al-Kamil fi al-Tarikh, jilid 3, hlm. 275
}

penggantinya. Munawir Sadzali menilai bahwa Muawiyah dalam mendapatkan kekuasaan dan mewariskannya melalui ketajaman pedang dan tipu muslihat. ${ }^{17}$

Keputusan itu direkayasa oleh Muawiyah seolah-olah mendapat dukungan dari pejabat penting pemerintah. Ia memanggil para Gubernur datang ke Damaskus agar mereka membuat semacam kebulatan tekad mendukung keputusannya. Ia meminta salah seorang Gubernur yang bernama al-Dahhaq bin Qais al-Fahri agar setelah ia berpidato dan memberi nasehat dalam suatu pertemuan, minta izin berbicara dengan memuji Allah dan menyatakan, Yazid bin Muawiyah adalah orang yang pantas memangku jabatan Khalifah setelah Muawiyah. Kepada para Gubernur lain diminta oleh Muawiyah agar membenarkan ucapan Dahhaq. Mereka memenuhi perintah itu, kecuali Gubernur Ahnaf bin Qais. ${ }^{18}$ Walaupun Muawiyah merubah sistem pemerintahan menjadi monarki, namun Dinasti ini tetap memakai gelar Khalifah. Bahkan Muawiyah menyebut dirinya sebagai Amir al-Mukminin. Dan status jabatan Khalifah diartikan sebagai wakil Allah dalam memimpin umat dengan mengaitkannya kepada al-Qur'an (surat al-Baqarah: 30). Atas dasar ini Dinasti Umayyah menyatakan bahwa keputusan-keputusan Khalifah didasarkan atas perkenan Allah. Siapa yang menentangnya adalah kafir.

Jika kebijakan Muawiyah dalam merubah sistim pemerintahan ini kita anggap sebagai dosa besar yang harus dipikul oleh Mu'awiyah, rasanya juga tidak adil karena penilaian kita terhadap sejarah masa lalu juga dipengaruhi oleh bias politik dan subjektivitas penulis sejarah. Dalam menganalisa kebijakan Muawiyah bin Abi Sufyan ini perlu dilihat beberapa sisi pandang: [1] Islam bukanlah satu-satunya negara yang ada di dunia ketika itu. Di luar Islam ada tiga negara besar

17 Munawir Sjadzali, Islam dan Tata Negara : Ajaran, sejaran dan Pemikiran, (Jakarta: UI Press, 1993), hlm. 34

${ }^{18}$ J. Suyuthi Pulungan, Fiqh Siyasah : Ajaran, Sejarah dan Pemikiran, Jakarta: Rajawali Pers, 2002), hlm. 167 
Byzantium, Persia dan Cina. Tiga negara yang disebutkan terakhir ini menganut sistem monarkhi. Muawiyah sebagai mantan Gubernur Damaskus sangat memahami ini karena beliau banyak berinteraksi dengan mereka; [2] Alasan geografis dan wilayah barangkali salah satu aspek penting yang harus dikedepankan. Mengingat wilayah kekuasaan Islam pada saat itu luas, sementara pada sisi lain jarak tempuh yang begitu jauh antara satu kota dengan kota lainnya hanya dapat ditempuh dengan berjalan kaki dan menunggang binatang. Rasanya sangat sulit untuk mendapatkan kesepakatan yang bulat (ijmak) dalam memilih pemimpin pengganti Muawiyah. Hal ini juga ternyata secara de facto belakangan diketahui bahwa ijmak yang diakui itu hanya terjadi pada masa sahabat; [3] Realitas sejarah memberikan informasi bahwa pada masa itu hanya monarkhi yang diinginkan oleh umat. Pernyataan ini barangkali terlalu ekstrim. Tetapi ada hal yang perlu diperhatikan, yaitu setelah Ali bin Abi Thalib meninggal dunia, penduduk Irak mem-bai'at Hasan bin Ali bin Abi Thalib sebagai Khalifah pengganti Ali. Setelah Hasan bin Ali meninggal terjadi pula pem-bai'at-an Husin bin Ali sebagai Khalifah. ${ }^{19}$ Artinya kalaupun Muawiyah tidak "merebut" kekuasaan, maka sistem yang terjadi juga kemungkinan besar adalah monarkhi; [4] Muawiyah melakukan ini dalam rangka mewujudkan kemaslahatan. Karena kalau diserahkan kepada umat kemungkinan pertumpahan darahpun akan terjadi. Di sisi lain adanya seorang pemimpin merupakan hal yang dharuri. Dalam hal ini barangkali perlu dipertimbangkan pendapat Ibn Taimiyah :

$$
\text { ستون سنة من إمام جائر أصلح من ليلة واحدة بلا سلطان ." }
$$

"enam puluh tahun di bawah pemerintahan yang zalim jauh lebih baik dibandingkan satu malam tanpa pemimpin"

${ }^{19}$ Lihat Philip K. Hitti alih bahasa oleh R. Cecep Lukman Yasin dan Dedi Slamet Riadi, History of The Arabs, (Jakarta: Serambi, 2005), hlm. 235-236

${ }^{20}$ Ibn Taimiyah, Al-Siyasah...hlm. 138
Ketiga, Muawiyah memberi penghargaan kepada orang-orang yang berjasa dalam perjuangannya mencapai puncak kekuasaan. Seperti 'Amr bin 'Ash, ia diangkat kembali menjadi Gubernur di Mesir, al-Mughirah bin Syu'bah diangkat menjadi Gubernur di wilayah Persi. Ia juga memperlakukan dengan baik dan mengambil hati para sahabat terkemuka yang bersifat netral terhadap berbagai kasus yang timbul waktu itu, sehingga mereka berpihak kepadanya. Hal ini dilakukan oleh Mu'awiyah dalam rangka mengamalkan ayat al-Qur'an yang menyebutkan bahwa orang yang berbuat baik (amal shalib) akan mendapatkan ganjaran kehidupan yang baik. Allah berfirman:

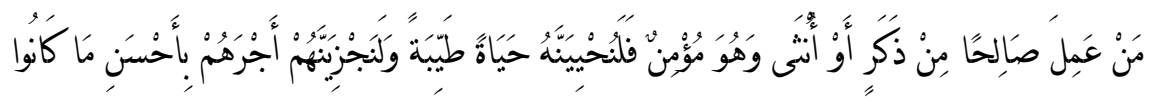

"Barangsiapa yang mengerjakan amal saleh, baik laki-laki maupun perempuan dalam keadaan beriman, maka sesungguhnya akan Kami berikan kepadanya kehidupan yang baik dan sesungguhnya akan Kami beri balasan kepada mereka dengan pahala yang lebih baik dari apa yang telah mereka kerjakan". (Q.S. An-Nahl: 97)

Keempat, menumpas orang-orang yang beroposisi yang dianggap berbahaya jika tidak bisa dibujuk dengan harta dan kedudukan, dan menumpas kaum pemberontak. Khalifah menumpas kaum Khawarij yang merongrong wibawa kekuasaannya dan mengkafirkannya. Golongan ini menuduhnya tidak mau berhukum kepada al-Qur'an dalam mewujudkan perdamaian dengan Ali bin Ali Thalib di perang shiffin melainkan ia mengikuti ambisi hawa nafsu politiknya.

Kelima, Khalifah-khalifah Dinasti Umayyah mengadakan pembaharuan di bidang administrasi pemerintahan dan melengkapinya dengan jabatan-jabatan baru yang dipengaruhi oleh kebudayaan Byzantium. Pengelolaan administrasi pemerintahan dan struktur pemerintahan Dinasti Umayyah merupakan penyempurnaan dari pemerintahan Khulara al-Rasyidin yang diciptakan oleh Umar ibi al- 
Khattab. Wilayah kekuasaan yang luas itu sebagaimana pada periode Negara Madinah, terbagi menjadi beberapa wilayah Provinsi. Setiap Provinsi dikepalai oleh Gubernur dengan gelar Wali atau Amir yang diangkat oleh Khalifah. Gubernur didampingi oleh seorang atau beberapa katib (sekretaris), seorang hajib (pengawal) dan pejabatpejabat penting lain, yaitu shabib al-kharaj (pejabat pendapatan), shabib al-syurthat (pejabat kepolisian) dan Qadbi (kepala keagamaan dan hakim). Pejabat pendapatan dan qadhi diangkat oleh Khalifah dan bertanggungjawab kepadanya.

Di tingkat pemerintahan pusat dibentuk beberapa lembaga dan departemen, al-katib, al-bajib dan diwan. Lembaga al-katib terdiri dari katib al-rasail (sekretaris Negara), katib al-Kharaj (sekretaris pendapatan Negara), katib al-jund (sekretaris militer), katib al-Syurthath (sekretaris kepolisian) dan katib al-qadhi (panitera). Katib al-rasail dianggap peling penting posisinya. Karena itu pejabatnya selalu orang terpercaya dan pandai serta dari keluarga kerajaan. Sekretaris yang terkenal selama masa pemerintahan Bani Umayyah adalah : [1] Ziyad bin Abihi, Sekretaris Abu Musa al-Asy'ari; [2] Salim, Sekretaris Hisyam bin Abd al-Malik; dan [3] Abdul Hamid, Sekretaris Marwan bin Muhammad.

Para katib bertugas mengurus administrasi Negara secara baik dan rapi untuk mewujudkan kemaslahatan Negara. Al-hajib (pengawal dan kepala rumah tangga istana) bertugas mengatur para pejabat atau siapapun yang ingin bertemu dengan Khalifah. Pada masa Dinasti Umayyah diadakan jabatan baru, al-hijabah yaitu urusan pengawalan Khalifah. Pengawalan Khalifah ini nampak jelas dalam kepemimpinan Khalifah Abdul Malik bin Marwan. Ketika Khalifah melantik pengawalnya, ia memberikan amanat : "Engkau telah kuangkat menjadi Kepala Pengawalku. Siapapun tidak boleh masuk tanpa izinmu, kecuali muazzin, pengantar pos dan pengurus dapur“". Lembaga ini belum dikenal di zaman Negara Madinah. Karenanya siapa saja boleh bertemu dan berbicara langsiung dengan Khalifah tanpa melalui birokrasi tapi ada tiga orang yang boleh langsung bertemu dengan Khalifah tanpa hajib, yaitu muadzdrin untuk memberitahukan waktu shalat kepada Khalifah, shabib al-barid (pejabat pos) yang membawa berita-berita penting untuk Khalifah, dan shabib al-tha'am (petugas yang mengurus hal ihwal makanan di Istana. Lembaga al-syurthath yang dipimpin oleh shabib al-syurtath bertugas memelihara keamanan masyarakat dan Negara.

Lembaga lain adalah bi bidang pelaksanaan hukum, yaitu alnizham al-qadha'i terdiri dari tiga bagian, yaitu al-Qadha, al-hisbah dan almazhalim. Badan al-Qadha dipimpin oleh seorang qadhi yang bertugas membuat fatwa-fatwa hukum dan peraturan yang digali langsung dari al-Qur'an, sunnah Rasulullah SAW, ijma' atau berdasarkan ijtihad. Badan ini bebas dari pengaruh penguasa dalam menetapkan keputusan hukum terhadap para pejabat, pegawai Negara yang melakukan pelanggaran. Pejabat badan al-bisbah disebut al-mubtasib, tugasnya menagani kriminal yang perlu penyelesaian segera. Pejabat badan almazhalim disebut qadhi al-mazhalim atau shabib al-mazhazlim. Kedudukan badan ini lebih tinggi dari al-qadha dan al-bisbah. Karena badan ini bertugas meninjau kembali akan kebenaran dan keadilan keputusankeputusan hukum yang dibuat oleh qadhi dan mubtashib. Bila ada suatu kasus perkara yang keputusannya dianggap perlu ditinjau kembali baik perkara seorang rakyat maupun pejabat yang menyalahgunakan jabatannya, badan ini menyelenggarakan mahkamat al-marhalim, yang mengambil tempat di masjid. Sidang ini dihadiri oleh lima unsur lengkap, yaitu para pembantu sebagai juri, para hakim, para fuqaha', para katib dan para saksi, yang dipimpin oleh qadbi al-mazhalim. Berarti pemerintahan Dinasti Umayyah, sebagaimana pada periode Negara Madinah, peradilan bebas tetap dilaksanakan.

Dalam tubuh organisasi pemerintahan Dinasti Umaiyyah juga dibentuk beberapa diwan atau departemen. [1] diwan al-rasail, departemen yang mengurus surat-surat Negara dari Khalifah kepada para Gubernur atau menerima surat-surat dari Gubernur. Departemen ini memiliki dua sekretariat, untuk pusat menggunakan bahasa Arab, dan untuk daerah menggunakan bahasa Yunani dan bahasa Persia. Tapi pada masa Khalifah Abd al-Malik diadakan arabisasi, yaitu hanya 176 
menggunakan bahasa Arab dalam surat-surat Negara. Politik Arabisasi ini berlanjut pada masa putranya Khalifah al-Walid, yaitu penggunaan bahasa Arab sebagai linguafranca dan bahasa ilmu pengetahuan untuk seluruh wilayah pemerintahan. Pengaruhnya berlanjut sampai sekarang. Misalnya Mesir dan Irak menggunakan bahasa Pahlawi dan Kipti, dan Damaskus bahasa Grek, ini menggunakan bahasa Arab. Kebijaksanaan ini mendorong seorang ulama Syibawaihi, untuk menyusun al-kitab yang selanjutnya menjadi pegangan dalam soal tata bahasa Arab. [2] diwan al-katib, Departemen Pencatatan yang bertugas menyalin dan meregistrasi semua keputusan Khalifah atau peraturanperaturan pemerintah untuk dikirim kepada pemerintahan di daerah. [3] diwan al-Kharaj, Departemen Pendapatan Negara yang diperoleh dari al-kharaj, 'usyur, zakat, jizyah, fai dan ghanimah dan sumber lain. Semua pemasukan keuangan yang diperoleh dari sumber-sumber itu disimpan di Bait al-Mal (Kantor Perbendaharaan Negara). [4] Diwan alBarid, Departemen Pelayanan Pos yang bertugas melayani informasi tentang berita-berita penting di daerah kepada pemerintah pusat dan sebaliknya, sehingga Khalifah dapat mengetahui apa yang terjadi di daerah dan memudahkannya untuk mengontrol jalannya pemerintahan di daerah. [5] Diwan al-Jund, Departemen Pertahanan yang bertugas mengorganisir militer. Personilnya mayoritas orang-orang Arab.

Adapun kebijakan pemerintahan Dinasti Umayyah dalam bidang siyasah kharijiyah antara lain dalam bentuk:

Pertama, meneruskan perluasan wilayah kekuasaan Islam baik ke Timur maupun ke Barat. Perluasan wilayah ini diteruskan oleh para penerus Muawiyah, seperti Khalifah Abd al-Malik ke Timur, Khalifah Abd al-Walid ke Barat dan ke Perancis di zaman Khalifah Umar bin Abd al-Aziz. Perluasan wilayah di zaman Dinasti Umaiyah merupakan ekspansi besar kedua setelah ekspansi besar pertama di zaman Umar bin Khattab. Daerah-daerah yang dikuasai umat Islam di zaman Dinasti ini meliputi Spanyol, Afrika Utara, Suriah, Palestina, Semenanjung Arabia, Irak, sebahagian dari Asia kecil, Persia, Afganistan, daerah yang sekarang disebut Pakistan, Rukmenia, Uzbek dan Kirgis di Asia tengah dan pulau-pulau yang terdapat di laut tengah, sehingga Dinasti ini berhasil membangun Negara besar di zaman itu. Bersatunya berbagai suku bangsa di bawah naungan Islam melahirkan benih-benih peradaban baru yang bercorak Islam, sekalipun bagi Umaiyah lebih memusatkan perhatiannya kepada pengembangan kebudayaan Arab. Benih-benih peradaban baru itu kelak berkembang pesat di zaman Dinasti Abbasiyah, sehingga dunia Islam menjadi pusat peradaban duia selama berabad-abad.

Kedua, baik Muawiyah, maupun para penggantinya membuat kebijaksanaan yang berbeda dari zaman khulafa al-rasyidin. Mereka merekrut orang-orang non muslim sebagai pejabat-pejabat dalam pemerintahan, seperti penasehat, administrator, dokter dan di kesatuan-kesatuan tentara. Tapi di zaman Khalifah Umar bin Abd alAziz kebijaksanaan itu ia hapuskan. Karena orang-orang non muslim (Yahudi, Nasrani dan Majusi) yang memperoleh privilege di dalam pemerintahan banyak merugikan kepentingan umat Islam. Bahkan menganggap rendah mereka. Dalam al-Qur'an memang terdapat peringatan-peringatan yang tidak membolehkan orang-orang mukmin merekrut orang-orang non muslim sebagai teman kepercayaan dalam mengatur urusan orang mukmin, tetapi ada ayat lain yang membolehkannya.

Ketiga, membangun kekuatan militer yang terdiri dari tiga angkatan, darat, laut dan kepolisian yang tangguh dan loyal. Mereka diberi gaji yang cukup, dua kali lebih besar daripada yang diberikan Umar bin Khattab kepada tentaranya. Ketiga angkatan ini bertugas menjaga dan menjamin stabilitas keamanan dalam negeri dan mendukung kebijaksanaan politik luar negeri, yaitu memperluas wilayah kekuasaan.

Adapun kebijakan pemerintahan Dinasti Umayyah dalam bidang siyasah maliyah antara lain dalam bentuk:

Sumber pemasukan negara pada masa Dinasti Umayyah pada dasarnya sama dengan apa yang berlaku pada masa Khulafa al- 
Rasyidin. Kewajiban yang harus dibayar oleh warga negara berupa pajak. Hanya saja mereka membedakan jumlah pajak yang dibebankan kepada umat Islam dengan penduduk non muslim yang berada dalam negeri-negeri yang baru ditaklukkan.

Adapun distribusi baitul mal diperuntukkan : [1] gaji pegawai dan tentara serta biaya tata usaha negara; [2] pembangunan pertanian dan termasuk irigasi; [3] ongkos bagi orang-orang hukuman dan tawanan perang; [4] pembelian perlengkapan perang; dan [5] hadiahhadiah kepada para pujangga dan ulama. ${ }^{21}$

\section{Kesimpulan}

Dari uraian di atas dapat disimpulkan bahwa Khalifah adalah jabatan sekuler dan berfungsi sebagai kepala pemerintahan eksekutif. Dinasti Umayyah ini lebih banyak mengarahkan kebijaksanaan pada perluasan kekuasaan politik atau perluasan wilayah kekuasaan negara. Dinasti ini bersifat eksklusif karena lebih mengutamakan orang-orang berdarah Arab duduk dalam pemerintahan, orang-orang non Arab tidak mendapat kesempatan yang sama luasnya dengan orang-orang Arab. Qadhi (hakim) mempunyai kebebasan dalam memutuskan perkara. Di samping itu Dinasti ini tidak meninggalkan unsur agama dalam pemerintahan. Formalitas agama tetap dipatuhi dan terkadang menampilkan citra dirinya sebagai pejuang Islam. Ciri lain Dinasti ini kurang melaksanakan musyawarah. Karenanya kekuasaan Khalifah mulai bersifat absolut. Dengan demikian tampilnya pemerintahan Dinasti Umayyah yang mengambil bentuk monarki, merupakan babak kedua dari praktek pemerintahan umat Islam dalam sejarah.

\section{Bibliografi}

${ }^{21}$ Lihat A. Hasjmy, Sejarab Kebudayaan Islam, (Jakarta: Bulan Bintang, 1995), hlm. 174
A. Djazuli, Fiqh Siyasah : Implementasi Kemaslabatan Umat dalam Ramburambu Syari'ah, (Jakarta: Kencana, 2007).

A. Hasjmy, Sejarah Kebudayaan Islam, (Jakarta: Bulan Bintang, 1995).

Azhari, Muhammad Tahir, Negara Hukum: Suatu Studi tentang Prinsipprinsipnya Dilihat dari Segi Hukum Islam, Implementasinya pada Periode Negara Madinah dan Masa Kini, (Jakarta: Bulan Bintang, 1992).

Azra, Azyumardi, Historiografi Islam Kontemporer: Wacana, Aktualitas dan Aktor Sejarah, (Jakarta: Gramedia 2002).

Bagdadiy, Ahmad bin Ishak bin Ja'far bin Wahab bin Wadhih alYa'kubiy, Tarikh al-Ya'qubiy, (Beirut: Daar al-Kutub alIlmiah, 1999), Juz 2.

Bek, Syeikh Muhammad al-Khudlariy, Tarikh al-Tasyri' al-Islamiy, (Jakarta: Daar al-Kutub al-Islamiyah, 2008).

Hitti, Philip K., alih bahasa oleh R. Cecep Lukman Yasin dan Dedi Slamet Riadi, History of The Arabs, (Jakarta: Serambi, 2005).

Ibn Katsir al-Dimasyqiy, Abu al-Fida' al-Hafizh, Al-Bidayah wa alNihayah, (Beirut: Daar al-Kutub al-Ilmiah, 2001).

Ibn Manzur, Lisan al-Arab, (Beirut: Daar al-Shadir, 1990), jilid VI dan VII.

Ibn Qayyim al-Jauziyah, Muhammad bin Abu Bakar, (ditahqiq oleh Muhammad Jamil Ghazi), Al-Thuruq al-Hukumiyyah fi alSiyasah al-Syar'iyyah, (Kairo: Mathba'ah al-Madaniy, t.th.).

Ibn Taimiyah, Syeikh al-Islam Taqiy al-Din Ahmad, Al-Siyasab alSyar'iyyah fi Isblah al-Ra'iy wa al-Ra'iyah, (Beirut: Daar alKutub al-Ilmiyah, 2000).

Philips, Abu Ameenah Bilal, alih bahasa oleh M. Fauzi Arifin, Asal Usul dan Perkembangan Fiqh: Analisis Historis atas Mazhab, Doktrin dan Kontribusi, (Bandung: Nusamedia, 2005). 
Pulungan, J. Suyuthi, Fiqh Siyasah : Ajaran, Sejarah dan Pemikiran, (Jakarta: Rajawali Pers, 2002).

Sirry, Mun'im A., Sejarah Fiqih Islam : Sebuah Pengantar, (Surabaya: Risalah Gusti, 1996).

Sjadzali, Munawir, Islam dan Tata Negara : Ajaran, sejaran dan Pemikiran, (Jakarta: UI Press, 1993).

Suyuthi, Hafizh Jalal al-Din Abd al-Rahman, Tarikh al-Khulafa, (t.tp: Daar al-Kutub al-Islamiyah, t.th.).

Syaibaniy, Imam al-'Allamah 'Umdat al-Muarrikhin Abu Hasan Ali bin Abu al-Karam Muhammad bin Muhammad bin Abd alKarim bin Abd al-Wahid, lebih dikenal dengan Ibn Atsir, Al-Kamil fi al-Tarikh, (Beirut: Daar al-Kutub al-Ilmiah, 1998). 